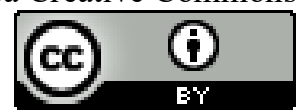

\title{
UBUHLE: VALORES SOCIAIS NA LUTA CONTRA O COLONIALISMO ESTÉTICO
}

\author{
Aline Tomaz dos Santos ${ }^{1}$ \\ Belo Horizonte, MG, Brasil
}

\begin{abstract}
Resumo: A descaracterização estética foi uma das muitas atrocidades utilizadas pelo sistema colonial para desorganizar grupos de pessoas vindas de África. Em contrapartida, a história relata a centralização da estética negra nos movimentos sociais dessa comunidade, tal como o Black Power e o Rastafari. Este trabalho apresenta uma pesquisa exploratória com o objetivo de compreender se e/ou como os valores sociais agregados aos serviços estéticos prestados em um salão afro de Belo Horizonte contribuem para o empoderamento e a emancipação de pessoas negras. Os dados foram coletados através de depoimentos de frequentadores do Salão Ubuhle. A partir da análise e da relação de fragmentos dos depoimentos com os valores aplicados, permitiu-se concluir que os valores sociais implementados ao protocolo de atendimento do salão podem auxiliar pessoas negras no seu processo de emancipação individual.
\end{abstract}

Palavras-Chaves: Beleza negra; Salão Afro; Empoderamento; Black Power.

\section{UBUHLE: SOCIAL VALUES IN THE FIGHT AGAINST AESTHETIC COLONIALISM}

\begin{abstract}
Aesthetic destruction was one of the many atrocities employed by colonialism to disrupt groups of people coming from Africa, but history shows a centralization of black aesthetics in the social movements of the Black community, such as afros and box braids. This work presents an exploratory research in order to understand whether the social values added to the cosmetic services provided by a black-owned beauty salon in Belo Horizonte contribute to the empowerment and emancipation of black people. The data were collected from regulars at Salão Ubuhle. Through the analysis of excerpts from these conversations with the applied values, it was possible to conclude that the social values implemented to the customer service policies and procedures can assist black people in their individual emancipation process.
\end{abstract}

Keywords: Black beauty; Afro Saloon; Empowerment; Black Power.

\section{UBUHLE: VALORES SOCIALES EN LA LUCHA CONTRA EL COLONIALISMO ESTÉTICO}

\footnotetext{
1 Bacharel em Biomedicina (UFMG), afroempreendedora, associada da Associação Brasileira de Pesquisadores Negros (ABPN). E-mail: aline.ubuhle@gmail.com ; ORCID: https://orcid.org/0000-0002$\underline{1279-1730}$
} 
Resumen: La desfiguración estética fue una de las muchas atrocidades utilizadas por el sistema colonial para desorganizar a grupos de personas procedentes de África; en cambio, la historia relata la centralización de la estética negra en los movimientos sociales de esta comunidad, como el Black Power y el Rastafari. Este trabajo presenta una investigación exploratoria con el objetivo de comprender si y/o cómo los valores sociales añadidos a los servicios estéticos prestados en una peluquería afro en Belo Horizonte contribuyen al empoderamiento y la emancipación de la población negra. Los datos se recogieron a través de testimonios de los visitantes de la peluquería Salão Ubuhle. A partir del análisis y la relación de fragmentos de los testimonios con los valores aplicados, se pudo concluir que los valores sociales implementados al protocolo de asistencia de la peluquería pueden ayudar a los negros en su proceso de emancipación individual.

Palabras-clave: Belleza negra; Peluquería Afro; El empoderamiento; El Poder Negro.

\section{UBUHLE: LES VALEURS SOCIALES DANS LA LUTTE CONTRE LE COLONIALISME ESTHÉTIQUE}

Résumé: La perte du caractère esthétique était l'une des nombreuses atrocités utilisées par le système colonial pour désorganiser des groupes de personnes venues d'Afrique, en contre-partie, l'histoire relate la centralisation de l'esthétique noire dans des mouvements sociaux de cette communauté, tels que le Black Power et le Rastafari. Ce travail présente une recherche exploratoire afin de comprendre si et/ou comment les valeurs sociales agrégées aux services esthétiques proposés dans un salon afro de Belo Horizonte contribuent à l'autonomisation et à l'émancipation de personnes noires. Les données ont été collectées à travers des témoignages des personnes fréquentant le Salon Ubuhle. À partir de l'analyse et de la relation des fragments des témoignages, valeur appliquée, il a été conclu que les valeurs sociales implantées aux protocoles de réception du salon peuvent aider les personnes noires dans le processus d'émancipation individuelle.

Mots-clés: Beauté noire; Salon Afro; Autonomisation; Black Power.

\section{INTRODUÇÃO}

A partir de uma pesquisa exploratória realizada entre junho/2018 e julho/2020, apresenta-se um texto que tem como objetivo compreender se e/ou como os valores sociais agregados aos serviços estéticos prestados em um salão de beleza afro belorizontino, contribuem para a ampliação da consciência sobre a questão racial em seus frequentadores. Ao favorecer o empoderamento e a emancipação de pessoas negras clientes do local, bem como possibilitar uma maior análise acerca desta questão envolvendo a localização do salão, sendo no bairro Savassi, em Belo Horizonte.

Este trabalho foi redigido durante um período em que o salão esteve com seu funcionamento suspenso, em cumprimento das medidas sanitárias adotadas pelo município para contenção da pandemia da COVID-19. Nesse sentido, percebemos, então, 
a importância da compreensão e catalogação dos processos não-comerciais realizados no espaço. Desta forma, é possível ter noção se os frequentadores percebem tais processos ou não; o que, em caso positivo, nos leva a questionar como eles os percebem.

Os chamados "salões de beleza afro" propõem-se ao acolhimento das especificidades negras. Por isto, possuem espaços que contêm profissionais especializados no cuidado com o cabelo crespo, a pele retinta e a aplicação de técnicas para o embelezamento de pessoas com tais características fenotípicas. O tratamento e o consequente cuidado com a estética evidenciam, então, seus papéis na afirmação identitária; bem como no fortalecimento da subjetividade e da criação de novos processos de subjetivação (estilos de vida e cultura). Eles o fazem ao implicar o amadurecimento e a contínua ampliação da consciência negra.

O tratamento e o cuidado da estética tal como tem sido desenvolvido em salões especializados, - popularmente denominados "beleza negra" - são instrumentos ascendentes do movimento antirracista. O salão - por constituir um espaço direcionado para pessoas que sobrevivem a um sistema de não-lugar — se comporta como um elemento de transformação. Entretanto, outros valores sociais podem ser explorados para potencialização da maquinaria de movimentos sociais antirracistas em prol da causa negra.

\section{DESENVOLVIMENTO}

Estudos prévios nas áreas de História, Antropologia e Sociologia atestam que o modo como pessoas negras lidam com a própria estética dialoga frequentemente com as pautas reivindicatórias dos movimentos sociais negros. Pesquisas demonstram como as características físicas influenciam nos processos de busca por direitos da população negra. Um exemplo disto é o movimento "Black Power", um dos movimentos que surgiu nos Estados Unidos com o objetivo de garantir direitos civis para negros. O movimento foi liderado pela Associação Nacional para o Avanço de Pessoas de Cor, National Association for the Advancement of Colored People (NAACP) em inglês, tendo como integrantes Malcolm X e Martin Luther King. Com o slogan “Black is Beautiful”, o movimento utilizou-se da valorização da beleza afro-americana, tais como os cortes de cabelo arredondados, ouriçados e volumosos, de modo que se identificassem e se organizassem sociopoliticamente (VAUGHAN, 2000). Nesse período, há uma evidenciação do orgulho das origens africanas performadas em ações cotidianas: 
"Quando, na década de 60, os negros começaram a rejeitar o padrão americano de beleza branca e ter mais orgulho das suas origens africanas, esta atitude foi refletida numa nova maneira de se vestir, de fazer o cabelo, de se tratar fisicamente" (VAUGHAN, 2000, p. $61)$.

Outro movimento social que exemplifica a valorização estética como elemento de organização política são os "Dreadlocks", que, de acordo com Kuumba e Ajanaku (1998), simbolizou um movimento cultural e de formação de identidade coletiva. O ato de "dredar" o cabelo começou entre as comunidades afrodescendentes na década de 1970, ligado ao movimento Rastafari na Jamaica. O Rastafari caracterizou-se também por pregar o orgulho étnico africano e, principalmente, a valorização das raízes etíopes sobrepostas às inglesas. Ao verem imagens de líderes guerreiros etíopes, com os seus cabelos "dredados", os jamaicanos passaram a adotar o penteado como símbolo de luta e reconhecimento. No Brasil, vivenciamos um movimento que aconteceu, em sua maior parte, através das redes sociais: por meio de vídeos e postagens, blogueiras cacheadas ensinavam como passar pela transição capilar ${ }^{2}$ e cuidar de cabelos cacheados. Andrade (2012) fez uma análise sobre os grupos de Orkut com temática negra entre 2004 e 2011; uma mobilização que preconizou a de transição capilar nas demais redes. Mais uma vez, a estética se posiciona como um dos agentes de movimento social. Santana (2014) descreve como o movimento pró cabelos naturais se deu através de vídeos no site YouTube e grupos na rede social Facebook; além disso, traz relatos de pessoas que assumiram seus cabelos naturais e identificam nisso um ato de resistência.

Já quando analisamos as significações pré-coloniais como, por exemplo, a cosmologia Iorubá, são encontrados registros do cabelo ocupando a posição de centralidade na cultura. A feição negra é, portanto, assinalada como um fator significativo presente nas culturas afros antes da colonização. Babatunde (1942) traz referências a partir da cosmologia Iorubá sobre o cabelo: diferente dos animais biologicamente inferiores - pois estes possuem um crescimento do cabelo uniforme por todo corpo o cabelo do homo sapiens ou omo adáríhurun ${ }^{3}$ é concentrado na cabeça (irun orí) de forma mais desenvolvida. Isto traz a ideia de que um santuário se faz presente na cabeça (orí) dos humanos. Além disso, a estilização dos cabelos, ou seja, a forma de trançar,

\footnotetext{
${ }^{2}$ TRANSIÇÃO CAPILAR: processo em que se interrompe o uso de alisante, retirando assim toda a química do cabelo.

${ }^{3}$ OMO ADÁRIHURUN: em Iorubá: homem em que o cabelo cresce principalmente na cabeça
} 
pentear e adornar, na cosmologia citada, pode ter significados como o status matrimonial; a indicação de poder; a demonstração de afiliação a determinado povo ou etnia; a indicação de papel e de ocupações sociais.

A colonização e o sistema de escravidão levaram para o mundo a ideia de subjugação da raça negra. Uma das heranças da colonização, uma lástima histórica, foi a supervalorização da estética européia em detrimento de outras - especialmente aquelas que valorizavam a beleza de pessoas negras. A mestiçagem ${ }^{4}$, o racismo, o eugenismo ${ }^{5} \mathrm{e}$ tantas outras mazelas pelas quais passam o povo negro compõem a herança colonial.

Inúmeras foram as torturas realizadas contra pessoas africanas - que foram escravizadas, transportadas por navios negreiros e comercializadas. Uma das táticas utilizadas durante este período era o apagamento da estética, feita com o propósito de descaracterizar, desorganizar e desunir negros. As roupas eram retiradas, os cabelos raspados e os adornos arrancados. Feito isso, povos diversos, com múltiplas línguas, famílias e círculos sociais diferentes, eram todos misturados. Isto era feito para que a organização social coletiva entre os negros fosse impossibilitada.

Dentre as muitas formas de violência impostas ao escravo e à escrava estava a raspagem do cabelo. Para o africano escravizado esse ato tinha um significado singular. Ele correspondia a uma mutilação, uma vez que o cabelo, para muitas etnias africanas, era considerado uma marca de identidade $\mathrm{e}$ dignidade (GOMES, 2006, p. 7).

A prática de raspar os cabelos permaneceu em sua repetição. Shane e Graham White (1995) relataram, de forma sucinta, este fato entre escravistas estadunidenses no século XIX.

No entanto, alguns proprietários [de escravos] do século XVIII recorreram ao corte ou à raspagem de cabelo, como uma forma de punição, como por exemplo a jovem escrava Hannah que teve seu cabelo cortado de uma maneira muito irregular como uma forma de punição por ofensas (WHITE; WHITE, 1995, p. 49).

Como relatado por Shane White e Graham White (1995), para os donos de pessoas escravizadas, o cabelo era um meio de estabelecer comunhão, “A maneira que os escravos afro-americanos utilizavam seus cabelos era muito importante para eles como indivíduos, além de ocupar um papel substancial em suas vidas em comunidade" (WHITE; WHITE,

\footnotetext{
${ }^{4}$ MESTIÇAGEM: cruzamento entre raças; neste caso, refere-se a um fenômeno colonial de moralização, que pregava o clareamento das gerações como uma forma de "purificar" a população brasileira.
}

${ }^{5}$ EUGENISMO: processo de "melhoramento", neste caso, de embranquecimento. 
1995, p. 46). O mecanismo de descaracterização da estética negra para anular a organização política destes é utilizado até hoje. Ao adaptar-se e atualizar-se às condições contemporâneas, ele apresenta um funcionamento eficaz condizente com seus usos originais.

"Corpo e cabelo como símbolos da identidade negra" (2006), da professora Nilma Lino Gomes, nos ajudam a compreender como o cabelo crespo e corpo negro não são apenas expressões fenotípicas biológica - ambos corroboram para a construção da simbologia identitária negra. Logo, a identidade negra não se constrói apenas sob o olhar do indivíduo para si, mas também como ele é visto, e que lugar ocupa na sociedade em termos de política e ideologia. Esta interlocução entre reconhecimento do individual e do grupo contribui para a presença da estética e identidade negras nos movimentos sociais deste grupo.

\section{ENTENDENDO AS FACES DA MANIFESTAÇÃO SOCIAL}

Axel Honneth (2013) em seu dossiê sobre reconhecimento e força motriz dos grupos, discorre a respeito da dependência individual de experiências sociais. A grosso modo, o autor menciona a importância da movimentação individual para que, por sua vez, o indivíduo possa se reunir e manifestar-se através de um grupo. Ao se ter como exemplo o movimento de transição capilar presente no Brasil desde 2010, cada menina que acompanhou os tutoriais na internet, se inteirou dos ensinamentos, praticou-os, viu a raiz crespa aparecer, soube o que é passar por todos os olhares condenatórios e racistas, tratase do individual dentro do social. Por meio destas experiências, esse movimento gera identificação dentro de um grupo que possui características e ideologias parecidas.

Tanto as manifestações sociais quanto as manifestações individuais não acontecem de forma isolada, e nem cronologicamente separadas. Para explicar a concomitância das duas manifestações, lançamos mão do conceito de Ubuntu, palavra bantufona ${ }^{6}$ que carrega um significado filosófico um tanto quanto potente: "Em linhas gerais, 'ubu' indica tudo que está ao nosso redor, tudo que temos em comum. 'Ntu' significa a parte essencial de tudo que existe, tudo o que está sendo e se transformando" (NOGUERA, 2011, p. 148). Noguera discute ainda o significado da máxima zulu umuntu

\footnotetext{
${ }^{6}$ BANTUFONA: de origem linguística Bantu.
} 
ngumuntu ngabantu (uma pessoa só é uma pessoa através de outras pessoas), ou seja, um indivíduo só é personificado através do pertencimento à sua comunidade. Reconhecer-se como parte de um todo é vital para a comunidade e para o indivíduo. Portanto, o movimento individual é iniciado e/ou continuado por influência da manifestação em sociedade; em contrapartida, o movimento social não acontece sem a contribuição de cada indivíduo.

Acredita-se que o fortalecimento da autoestima, da representatividade, da educação, o fomento ao autocuidado, a escuta e a empatia, associados, são valores incidentes nas vias de fortalecimento individual de pessoas negras no movimento de resistência. Baseando-se nesses valores, a Ubuhle foi criada.

Idealizada e operada por profissionais negras, Ubuhle é um empreendimento no ramo da beleza, que tem como missão a promoção do autocuidado da população negra da cidade de Belo Horizonte, em Minas Gerais.

\section{O SIGNIFICADO DE UBUHLE}

Ao iniciar um empreendimento, é necessária a criação de um nome fantasia, pelo qual o público irá conhecer o negócio. Com o foco em oferecer serviços para pessoas negras, o salão buscou referências africanas para que houvesse uma conexão com o público. Optou-se então por Ubuhle, uma palavra de origem Bantu ${ }^{7}$, que significa beleza, bondade e excelência. Pela dúvida na correta maneira da pronúncia, a princípio, o nome não foi aceito pelo público. Através do trabalho de divulgação realizado pelo salão, essa barreira foi quebrada e, após algum tempo, houve a conexão inicial esperada. Ubuhle nasce, então, como uma alternativa de trabalho para sua idealizadora, que estava nos anos finais de sua graduação em Biomedicina. Nesse período, além de se cumprir as disciplinas teóricas e práticas; estágio obrigatório e o trabalho de conclusão de curso de sua graduação, era preciso que ela conciliasse com uma rotina do salão. Após um ano de atendimentos itinerantes, a Ubuhle inaugurou sua primeira unidade, localizada no bairro Savassi, na cidade de Belo Horizonte, Minas Gerais.

Ao longo de dois anos sediado em um bairro nobre de Belo Horizonte, Ubuhle posicionou-se como um salão de beleza afro. "Afro" é a denominação utilizada para

\footnotetext{
${ }^{7}$ BANTU: grupo étnico e linguístico localizado em África.
} 
salões de beleza que oferecem serviços voltados para a população negra em Belo Horizonte, precedido pelo termo "salão étnico", de acordo com Nilma Lino (2006). Além disso, por conta de sua localização, Ubuhle tornou-se referência na cidade como um espaço de acolhimento. Isto porque fica localizada em um bairro central da capital mineira - Savassi - que é majoritariamente frequentado por pessoas brancas de classes sociais alta e média. Denominado "Quilombo da Beleza Negra" em uma matéria da Revista Canjerê (RODRIGUES, 2019), a idealizadora e as profissionais do local buscaram padronizar seus atendimentos, para que alguns dos valores fossem mais frequentemente empregados. No contexto do Salão Ubuhle, a palavra quilombo faz referência a um dos tantos significados que pode ter; segundo Ilka Boaventura Leite (2000), o termo quilombo é por vezes associado a "um estabelecimento singular" para o povo que nele vive, para as manifestações populares, ou como local de prática condenado pela sociedade.

Como dito anteriormente, um fator relevante para discussão é a localidade onde a primeira unidade da Ubuhle foi fundada. Na matéria da Revista Canjerê (RODRIGUES, 2019), uma das fundadoras da unidade afirma:

A Savassi em si não tem nada voltado para pessoas negras. Enfrentamos muito racismo de pessoas que nos maltratam e maltratam nossos clientes. Hoje, vemos o fato de a Ubuhle ser o único salão afro na região como algo positivo, porque a gente se enxerga como um ponto de resistência, e acaba sendo também um espaço político (TOMAZ, p.20, 2019).

Para aqueles que desconhecem a distribuição geográfica da cidade de Belo Horizonte, nota-se que a Savassi é um bairro situado na Zona Sul, concentra bares e restaurantes elitistas, além de um comércio voltado para clientela branca e das classes mais altas da cidade.

\section{VALORES DA UBUHLE}

A fundação e o funcionamento da Ubuhle estão pautados em valores que, para além do serviço estético, possam fomentar a manifestação individual. O propósito disto já foi previamente discutido, que se insere em um ou alguns movimentos aos quais os indivíduos queiram vir a pertencer. Fortalecimento da autoestima, representatividade, educação, autocuidado, escuta, empatia e acolhimento são os valores estabelecidos como fundamentais para o funcionamento do empreendimento. 


\section{Fortalecimento da autoestima}

Palavras de favorecimento, que expressam admiração, são empregues pelas profissionais do espaço em relação aos clientes como forma de fomentar a autoestima.

A autoestima, de acordo com Algarve (2004), consiste na maneira na qual a pessoa se relaciona com o próprio ser, com o ambiente e com as pessoas que convive; ela decorre de uma atitude positiva ou negativa perante a si mesma e perante o grupo ao qual pertence. Nos valemos aqui da discussão sobre como o racismo leva à uma autoavaliação negativa. Tais avaliações negativas tem relevância e consequências na comunidade, na cultura, na religião e nas características das pessoas negras. Em suma, o racismo faz com negros odeiem a si mesmos e seus semelhantes, ao firmar na comunidade uma aura de baixa autoestima que é alimentada individualmente.

Segundo Algarve (2004), a baixa autoestima é característica recorrente na população negra e gera nela sofrimento, pois ela enfrenta todos os dias rejeição, majoritária, devido às suas feições. Para além do cabelo, cor de pele, traços e estrutura corpórea, as pessoas negras também são desprezadas por sua situação econômica, já que são em sua maioria, pobres.

\section{Representatividade}

A representatividade se dá pela presença de um elemento, em determinado âmbito, a fim de representar um grupo, neste caso, o grupo de pessoas negras.

A mídia, com seu papel de registro e de retratação histórica, foi nomeada como um grande veículo de representatividade e, por isso, há o uso dessa ferramenta para discursar sobre o tema. De acordo com Daniel Silva, em sua tese de Trabalho de Conclusão de Curso (2015), a mídia tem papel fundamental para a formação de opinião da massa telespectadora. Padrões são criados, reforçados e multiplicados através dela. Silva (2015) chama atenção para o forte impacto que o conteúdo passado na TV causa na sociedade. Impacto é o que podemos chamar de o que acontece nas vidas das pessoas negras, que não se veem representadas, ou se veem mal representadas. De acordo com Honneth (2003, p. 213), "a falta de reconhecimento resulta em um comportamento danoso, que limita a compreensão positiva do indivíduo em relação a si mesmo". 
Correlacionando com o conceito de autoestima supradescrito, a falta de representatividade ou a má representatividade leva o indivíduo a ter uma autoestima baixa.

Por ter noção da importância da representatividade, há um cuidado para que o grupo de parceiras prestadoras de serviços que atuem na Ubuhle, seja prioritariamente negro. Isto tem por finalidade reforçar o estereótipo positivo acerca das profissionais negras. Além disso, a decoração do local inclui fotos de pessoas negras em vestes tradicionais de alguns povos africanos, para que os frequentadores possam ter referências de belezas a partir de uma perspectiva não-eurocêntrica. Outro fator considerado para a representatividade encontra-se no marketing e propaganda: logo, qualquer publicidade que for publicada nas redes sociais da Ubuhle, deve conter imagens de pessoas negras.

\section{Educação}

Nas redes sociais, durante os atendimentos e, principalmente, através de rodas de conversas, o valor da educação é aplicado. Reuniões e eventos abertos ao público para discussão de temas inerentes à população negra são realizados no salão desde a primeira unidade física. Neste momento, em meio a um bairro elitista belorizontino, é criado local para que pessoas pretas possam frequentar.

Segundo as professoras Petrolina Beatriz e Maria Guazzeli (2007), as Rodas de Conversas são um meio de discutir temas importantes, necessários e emergentes sem a necessidade de que dali saia uma conclusão definitiva. Pela informalidade e por seu formato, a roda permite maior troca entre seus participantes. Ela possui um mediador (ou mediadores) que aparece apenas como um fomentador do debate, ao trazer questões pertinentes ao tema, mas não representar nenhuma espécie de superioridade em sua fala.

\section{Autocuidado}

O autocuidado é um termo familiarizado entre os profissionais de enfermagem e seu conceito é constituído pelas atividades e atitudes que são praticadas em benefício do próprio indivíduo (BUB et al., 2006). O fato da população negra não ter aprendido a praticar o autocuidado em sua plenitude, justifica-se pelo fato de uma memória ancestral que se faz presente e necessária até os dias atuais, a sobrevivência. Ao ter sua noção de 
cuidado retirada pelo racismo, a população negra deve ter em mente que: Antes de praticar o cuidado com outro, é necessário ter uma vida própria para cuidar, porém pessoas negras carregam a sensação de estarem sempre a zelar pela sobrevida.

A Ubuhle propõe o autocuidado através da estética: o cuidado com o cabelo, a pele e as unhas são comunicadas como um processo necessário; o que, como já sabido, foi negado à população negra na maior parte do tempo. A comunicação enfatiza como a prática de cuidar de si é vital, e que isso não é desnecessário ou desperdício. Além disso, motiva a prática de cuidados considerados "mais simples", realizados pelos clientes em seus próprios lares.

\section{Escuta}

Escutar a demanda do cliente é uma prioridade. Acredita-se que a escuta seja uma forma de acolhimento (PASCUCCI, 2017). Escutar é diferente de ouvir: por ouvir considera-se apenas a capacidade de receber o que vem do outro em formato de som, o ato de escutar já indica o envolvimento de quem escuta com aquele que fala.

O ouvir autêntico, portanto, é um recolhimento concentrado, que pertence à multiplicidade do que é dito, auscultando-o como um todo coeso, perpassado por um sentido. Quando o homem assim escuta podemos então dizer que ele é "todo ouvidos", pois é todo recolhimento e concentração no dito. Não ouvimos, portanto, quando apenas escutamos meras palavras pronunciadas por alguém, mas quando pertencemos ao que está sendo dito (CORDEIRO apud PASCUCCI, 2015, p. 166).

\section{Empatia}

A empatia é tida como o ato de entender a vivência do outro ainda que por sua própria perspectiva; é a essência da comunicação e do compartilhamento (GRACIOSO; PARISE, 2017). Pessoas negras compartilham desde o sofrimento até a opressão infundada e injustificável, que é o que conhecemos como racismo. Agregado a isso vivemos um contexto social que minimiza o sofrimento dessa parcela da população, o que promove o silenciamento de suas angústias. Através da empatia, Ubuhle proporciona por alguns instantes o sentimento de liberdade e a possibilidade de partilha.

\section{Acolhimento}


Além dos valores da representatividade, da escuta e da empatia, algumas outras atitudes foram empregadas como parte do protocolo de atendimento para que os frequentadores do espaço pudessem se sentir acolhidos, em meio ao racismo e ao preterimento da estética afro-brasileira.

A recepção das pessoas com abraço, quando havia abertura; o oferecimento do café, bebida amplamente consumida pelos mineiros; e também a decoração, a disposição dos móveis no ambiente, além das músicas de fundo serem sempre de artistas negros, são elementos pequenos, mas importantes para a criação de um ambiente acolhedor e intimista.

\section{A COLETA DOS DEPOIMENTOS}

Os sete valores descritos acima foram empregados de maneira espontânea, adicionados à rotina de atendimentos de forma natural e não planejada. Contudo, com o passar do tempo, os valores foram incorporados a uma espécie de protocolo de atendimento, sendo aplicado a todo frequentador do Ubuhle.

Em outubro de 2019, um ano e seis meses após o início do funcionamento da Ubuhle Savassi, iniciou-se a coleta de depoimentos que se estendeu pelos meses de outubro e novembro. Mensagens foram enviadas a alguns frequentadores, solicitandolhes a gravação em áudio e/ou vídeo pelo WhatsApp de resposta para a seguinte pergunta: “Como a Ubuhle impactou sua vida enquanto uma pessoa negra?”. O objetivo inicial da ação era a criação de materiais para divulgação na internet. Os depoimentos não foram divulgados pelo responsável por gerenciar as plataformas digitais, infelizmente. Assim, em abril de 2020, é sugerido que tais depoimentos sejam objeto de pesquisa, desde que todos os envolvidos aceitem.

Todos os participantes consentiram em participar do projeto como objeto de pesquisa, por meio de um termo livre e esclarecido, aplicado via gravação de áudio no aplicativo Whatsapp em respeito às determinações de isolamento social em virtude da pandemia de COVID-19. Os demais depoimentos foram coletados em julho de 2020 através do aplicativo Whatsapp e com a mesma pergunta norteadora da primeira etapa de coleta. O critério de seleção para escolher os frequentadores que iriam gravar o vídeo ou áudio priorizou os que eram recorrentes e que acompanhavam a Ubuhle desde a fundação 
da sede, ou próximo a isso, incluindo clientes e parceiros. Todos os nomes usados são fictícios.

\section{Teni (Depoimento recebido em 18 de outubro de 2020).}

"É onde tem acolhimento, tem afeto, então eu me sinto amiga, eu me sinto parte e parceira da Ubuhle. Espaço onde podemos estabelecer esse tipo de relação, é um tipo de quilombo, de povo negro que é unido, que se reconhece e se empodera coletivamente. Além de cuidar da gente, preocupa com nossas especificidades, também forma as pessoas e isso é muito bonito."

\section{Nana (Depoimento recebidlo em 22 de novembro de 2020).}

"Bom, pensar na Ubuhle pra mim é pensar em aconchego, é pensar em pessoas que estão correndo juntas pro mesmo lugar de mãos dadas. Muito mais que um espaço para gente cuidar da nossa beleza, é um espaço pra gente cuidar do nosso emocional, da nossa alma. Durante a minha caminhada como empresária/empreendedora negra eu me senti muito solitária [...] às vezes fica muito pesado ser a exceção [...] é muito melhor quando a gente olha pro lado e vê pessoas crescendo juntas. [...] É uma rede muito incrível. Eu me sinto muito bem aqui, é um lugar onde eu vou de encontro com a minha essência, que eu posso cuidar de mim, [...] que eu tenho a oportunidade de admirar pessoas e me ver nessas pessoas. [...] Poder admirar pessoas negras talentosíssimas, que estão sendo reconhecidas e trazendo outras pessoas junto com elas."

\section{Anesu (Depoimento recebido em 28 de novembro de 2020).}

"Cheguei aqui neste lugar e eu super me identifiquei, porque tem pessoas parecidas comigo e são super admiráveis [...] Um lugar onde eu consegui trabalhar minha identidade [...] É muito importante este espaço aberto para gente conviver, cultivar essas raízes, ter contato com pessoas parecidas comigo e, com isso, construí minha identidade, aceitando e aprendendo a gostar das minhas características e a gostar mais de mim [...] A Ubuhle foi muito importante pra mim neste momento."

\section{Angelique (Depoimento recebido em 07 de jullho de 2021).}

"Quando a gente fala de consciência negra a gente fala de luta. A gente fala de confraternização, mas de luta. União, reunir e unir, e é aí que entra o projeto da Ubuhle, 
o projeto da Cel Turbantes e de tantos outros aí que vêm fazendo a diferença nas nossas vidas. Quando a gente fala dessa consciência negra, a gente fala de empoderamento, gente fala de embelezamento, a gente fala de crescimento. E é aí que entra a Ubuhle, trazendo essa autonomia, esse encorajamento para as pessoas, de ir ali, de se assumir bonita mesmo, de querer um cuidado pra ela, porque quando a gente cuida da gente, a gente tá apto a cuidar do outro. Então, primeiro você cuida da sua casa pra depois você cuidar da casa do outro, você cuidar do outro. Aí eu acho que é por aí, de trazer essa diferença aí na vida das pessoas. Eu me sinto representada aí junto a Ubuhle.”

\section{Yemi (Depoimento recebidlo em 07 de jullho de 2021).}

"Em relação à Ubuhle, o impacto na minha vida foi acertarem o meu corte de cabelo, que eu estava com a autoestima não muito legal por conta da falta de corte que eu tinha e, após fazer o corte, eu me senti mais autêntica; e todas as vezes que eu vou lá eu me sinto em casa, sou bem recebida, é como se eu tivesse dentro da minha casa. $\mathrm{O}$ ambiente familiar. [...] Sinto que minhas características enquanto mulher negra são valorizadas, até mesmo enquanto mulher, os traços, o cabelo e tudo mais."

\section{Tiwa (Depoimento recebidlo em 07 de jullho de 2021).}

"Conheci a Ubuhle através de um instagram de uma menina preta, que é ótima referência para cuidar de cabelo afro em Belo Horizonte. E a partir daí eu procurei a Ubuhle, porque me preocupo em consumir de pessoas pretas, sempre que posso, principalmente negócios de mulheres. E aí, quando decidi fazer isso, não estava muito preocupada com o que ia ser, como ia ser, estava preocupada em consumir de uma mulher preta. Eu achei que foi bem interessante minha experiência por vários motivos; o primeiro, a qualidade do serviço e o segundo motivo foi perceber o quanto a gente pode se fortalecer quando a gente percebe a parte boa e a parte do desafio da pessoa. Achei muito legal a proposta, achei muito legal o trabalho, achei a entrega muito, muito boa, mas o negócio precisava ser ajudado e a abertura para troca foi muito, muito grande. Então, o que eu penso quando eu vou consumir de uma pessoa preta é que eu pego todas as minhas experiências, a primeira coisa que senti foi acolhimento, receptividade e disposição para trocar informações. Porque o que geralmente acontece em outros lugares é que as pessoas não estão preocupadas em te ouvir e te acolher [...] e eu senti muito disso na Ubuhle, foi muito massa." 


\section{DISCUSSÃO}

$\mathrm{Na}$ análise dos depoimentos coletados, foram identificadas palavras que indicam relação com algum ou alguns dos valores aplicados na metodologia de atendimento da Ubuhle.

A autoestima é um valor frequentemente citado nos depoimentos e aparece nas falas dos frequentadores através dos trechos: “(...) é tipo um quilombo, de povo negro unido, que se reconhece e se empodera coletivamente”, diz Teni; “(...) com isso construiu minha identidade, aceitando e aprendendo a gostar das minhas características e gostar mais de mim", relata Anesu; Angelique também menciona: "E é aí onde entra a Ubuhle, trazendo essa autonomia, esse encorajamento para as pessoas, de ir ali, de se assumir bonita mesmo (...)”; “(...) eu estava com a autoestima não muito legal por conta da falta de corte que eu tinha e, após fazer o corte, me senti mais autêntica”, reporta Yemi.

$\mathrm{O}$ valor da representatividade pode ser percebido por meio do depoimento de Nana, "é um lugar (...) que eu tenho a oportunidade de admirar pessoas e me ver nessas pessoas". Anesu também percebe a aplicação do valor representatividade: "Cheguei aqui neste lugar e eu super me identifiquei, porque tem pessoas parecidas comigo e são super admiráveis"; Tiwa também destaca o quanto esse valor determinou sua escolha em visitar a Ubuhle: "não estava muito preocupada com o que ia ser, como ia ser, estava preocupada em consumir de uma mulher preta."

O valor da educação é citado por Teni no trecho: "Além de cuidar da gente, preocupa com nossas especificidades, também forma as pessoas e isso é muito bonito”.

O autocuidado é também um valor frequentemente percebido pelos frequentadores, como fica claro no depoimento de Teni: “Além de cuidar da gente, preocupa com nossas especificidades (...)"; "Muito mais que um espaço para gente cuidar da nossa beleza é um espaço pra gente cuidar do nosso emocional, da nossa alma”, diz Nana; Angelique reporta: “(...) porque quando a gente cuida da gente, a gente tá apto a cuidar do outro. Então primeiro você cuida da sua casa pra depois você cuidar da casa do outro, você cuidar do outro. Aí eu acho que é por aí, de trazer essa diferença aí na vida das pessoas". 
A escuta é um valor citado por Tiwa: "Porque o que geralmente acontece em outros lugares é que as pessoas não estão preocupadas em te ouvir e te acolher (...) e eu senti muito isso na Ubuhle, foi muito massa”.

Sobre a empatia, Teni discorre: "[A Ubuhle] preocupa com nossas especificidades"; Anesu destaca que "é muito importante este espaço aberto para gente conviver, cultivar essas raízes"; Angelique cita: "E é aí onde que entra a Ubuhle, trazendo essa autonomia esse encorajamento para as pessoas (...)"; Yemi diz: "Sinto que minhas características enquanto mulher negra são valorizadas, até mesmo enquanto mulher, os traços, o cabelo e tudo mais."; Tiwa relata que "a primeira coisa que senti foi (...) disposição para trocar informações”.

O valor acolhimento também foi amplamente citado pelos participantes. Teni cita: "É onde tem acolhimento, tem afeto, então eu me sinto amiga, eu me sinto parte e parceira da Ubuhle."; "Pensar na Ubuhle pra mim é pensar em aconchego.”, relata Nana; "É muito importante este espaço aberto para gente conviver.”, diz Anesu; Yemi diz: “(...) e todas as vezes que eu vou lá eu me sinto em casa, sou bem recebida, é como se eu tivesse dentro da minha casa. O ambiente é familiar."; Tiwa diz: "a primeira coisa que senti foi acolhimento."

A conclusão é de que alguns dos valores aplicados junto aos atendimentos e à prestação de serviços estéticos são percebidos pelos frequentadores. $\mathrm{O}$ efeito do valor representatividade, que expõe uma visão positiva de profissionais semelhantes aos frequentadores, ou seja, negras, é exposto nos depoimentos de Anesu e Nana. A palavra cuidado e suas variações aparecem em três dos seis depoimentos, o que sugere que o zelo pela estética nessas pessoas atinge algo mais profundo, para além da aparência física. As expressões "acolhimento", "me sinto em casa", "aconchego", "quilombo" podem estar relacionadas ao valor de acolhimento. Já "afeto", "parceria", "relação de amizade" relacionam-se mais com o valor da empatia, já que este valor está intimamente ligado à capacidade de nos relacionarmos com a vivência e os sentimentos do outro.

\section{CONCLUSÃO}

Os depoimentos revelam como os valores adotados pelo salão Ubuhle causaram transformações individuais em diferentes níveis. Expuseram também como a valorização dos traços negros é uma das vias para o desenvolvimento da autoestima e da elaboração 
de identidades positivas. Compreende-se que, assim como o início da manifestação social se dá no indivíduo e ocorre de maneira simultânea com a manifestação em grupo, a representatividade contribui para a formação da autoestima. Isto acontece pois é a partir do vislumbre de seu semelhante de maneira positiva que o indivíduo pode se apreciar de maneira igualmente positiva. Pode-se levantar uma hipótese na qual se infere que uma pessoa que se aprecia positivamente cria uma necessidade de autocuidado mais facilmente, em uma relação de causa e efeito, portanto só se cuida do que se acredita que tenha valor.

Através da educação, da escuta, da empatia e do acolhimento cria-se um ambiente propenso à comunhão e à partilha, tanto físicas como virtuais. A Ubuhle tornou-se um local de referência para reuniões e debates sobre temas que iam desde o cuidado; a autoestima; a saúde; o que é pertinente à estética negra; até assuntos de níveis mais abrangente socialmente, como posicionamentos políticos, economia negra (black money) e movimentos sociais. Esses valores, quando reúnem pessoas em formato coletivo, criam espaços de cidadania e humanidade, atributos estes que são constantemente negados à população negra. $\mathrm{O}$ cuidado coletivo traz a sensação de pertencimento racial, algo retirado brutalmente dela. A escuta, a empatia e o acolhimento, são frequentemente reservados para pessoas não-negras. Quando providenciadas de maneira comunitária, fortalece tanto indivíduos como comunidade.

Apesar de demonstrar compatibilidade com os valores aplicados ao protocolo de atendimento, os depoimentos também expõem uma carência e sugerem uma fragmentação entre os indivíduos dos movimentos negros. Uma sugestão de possível melhoria seria tornar os frequentadores da Ubuhle como participantes do que foi aqui discutido, retirando-os da posição de simples expectadores. Os frequentadores poderiam, então, conhecer os valores, como eles são aplicados e a importância de serem multiplicados entre a comunidade. Sugere-se, então, a implementação de um oitavo valor, o da reciprocidade, onde o cliente poderia participar ativamente dos eventos do salão de maneira a potencializar o movimento que já tem sido feito.

Historicamente, a estética das pessoas negras ocupa um papel funcional muito grande dentro da comunidade africana e afrodescendente, não só pela simples existência dos traços, mas também no modo como é performada e tratada. Há mais registros da influência cultural do cabelo - já que é o elemento corporal que protege a cabeça, de onde é emanado todo o comando do corpo do indivíduo — segundo algumas 
epistemologias africanas. O modo de usar o cabelo é um grande exemplo de identificação entre o grupo Iorubá, da qual muitos dos afro-brasileiros descendem. Na diáspora, há registro de movimentos sociais negros que foram fortemente marcados por elementos estéticos, como os então denominados black powers e os dreads. O papel de organização política, de status e de identidade do cabelo afro foram, diversas vezes, retirados dos negros de forma agressiva. Porém, como se estivesse registrado em sua memória ancestral, os movimentos sociais negros vêm, em sua maioria, associados à estética, resgatando esse papel.

O tratamento da estética por si já causa vários impactos, mas associado aos valores sociais que unem os negros, ela incentiva o autocuidado, reforça a alta da autoestima, corrobora a representatividade e produz comunhão. Este tratamento pode, então, ter seus efeitos catalisados. As pessoas negras vivem em constante luta; resistência e existência são conceitos que não se dissociam desta população, sobreviver e viver tampouco. Locais como a Ubuhle podem e devem ser pulverizados pelos espaços urbanos. Apesar das pontuadas melhorias a serem feitas, a "formação de quilombos" pode ser uma das tantas opções para permitir que tanto o movimento social individual quanto aquele que vem da união deste, possa agir coletivamente. Os povos ancestrais de África construíram tecnologias para garantir a sua sobrevida e a de seus descendentes, que, até hoje, continuam as adaptando, em busca da liberdade.

\section{REFERÊNCIAS BIBLIOGRÁFICAS}

ALGARVE, Valéria Aparecida. Cultura Negra na sala de aula: Pode um cantinho de Africanidades elevar a auto-estima de crianças negras e melhorar o relacionamento de crianças negras e brancas? Tese (Mestrado em Educação), Universidade Federal de São Carlos, São Carlos, SP, 2004.

ANDRADE, Melissa Maria de Freitas. Negritude em rede: discursos de identidade, conhecimento e militância - um estudo de caso da comunidade Negros do Orkut (2004-2011). Tese (Mestrado em Educação). Faculdade de Educação da Universidade de São Paulo, São Paulo 2012.

BUB, Maria Bettina Camargo et al . A noção de cuidado de si mesmo e o conceito de autocuidado na enfermagem. Texto contexto - enferm., v. 15, n. spe, p. 152-157, 2006.

GOMES, Nilma Lino, Sem perder a raiz: Corpo e cabelo como símbolos da identidade negra. Minas Gerais. Autêntica, 2006.

Gonçalves e Silva, Petronilha Beatriz, Guazzelli Bernardes, Nara Maria. Roda de conversas: Excelência acadêmica é a diversidade. Educação, v. XXX, n. 61, 2007, p. 53-92. 
GRACIOSO, Joel e PARISE, Maria Cecília Isatto. Eu puro e empatia segundo Edith Stein. Argumentos, V 9, n. 18, 2017, p. 60-73.

HONNETH, Axel Luta por reconhecimento: a gramática moral dos conflitos sociais. São Paulo: Editora 34:2003.

HONNETH, Axel. O eu no nós: reconhecimento como força motriz de grupos. Sociologias v.15 n. 33,2013 , p. $56-80$.

KUUMBA, M. e AJANAKU,Femi. Dreadlocks: The Hair Aesthetics of Cultural Resistance and Collective Identity Formation. Mobilization: An International Quarterly, v. 3, n. 2, 1998, p. $227-$ 243.

LAWAL, Babatunde. Orilonise: The Hermeneutics of the Head and Hair. Le monde l'art tribal, v. 7, n. 2, 2001, p. 80-99.

LEITE, Ilka Boaventura. Os quilombos no Brasil: Questões conceituais e normativas. Etnográfica, v. 4 n.2, 2000, p. 333-354.

NOGUERA, Renato. Ubuntu como modo de existir: Elementos gerais para uma ética afroperspectivista. Revista da ABPN, v. 3, n. 6, 2011, p. 147-150.

PASCUCCI, Maria Verónica. Sobre a escuta como acolhimento do outro: fragmentos de uma poética da escuta como caminho de formação humana. Conjectura: Filosofia e Educação, v. 22, n. 3, 2017, p. 561-575.

RODRIGUES, Naiara. Ubuhle: Quilombo da beleza negra no coração da Savassi. Revista Canjerê, Belo Horizonte, ano 12, p. 22-23, jun. 2019.

SANTANA, Bianca. Mulher, cabelo e mídia. Revista Communicare - Dossiê Feminismo, v. 14, n. 1,2014 , p. 132-144.

SANTOS, Daniel Silva. Mídia e racismo: uma análise da representatividade negra no seriado "Sexo e as negas". Tese (Bacharelado em Direito), Universidade de Brasília, Brasília, DF, 2015.

TOMAZ, Aline. Entrevista: Aline Tomaz. Entrevista concedida a Naiara Rocha. Ubuhle: Quilombo da beleza negra no coração da Savassi. Revista Canjerê, Belo Horizonte, ano 12, p. $22-$ 23, jun. 2019.

VAUGHAN, Patrícia Anne. A imagem americana de beleza física e as mudanças provocadas pelo "Black Power" na década de 60. Rev. de Letras, v. 1/2, n. 22, 2000, p. 59-62.

WHITE, Shane, and WHITE, Graham. Slave Hair and African American Culture in the Eighteenth and Nineteenth Centuries. The Journal of Southern History, v. 61, n. 1, 1995, p. 4576.

Recebido em: 17/02/2021

Aprovado em: 20/09/2021 